\title{
La fictohistoria o historiografía imaginaria en las literaturas románicas desde el siglo XIX: ensayo de tipología y panorama de un género formal insospechado (I)
}

\author{
Mariano MARTÍN RODRÍGUEZ \\ Universitatea «Babeş-Bolyai», Cluj-Napoca \\ martioa@yahoo.com
}

\begin{abstract}
RESUMEN
I. La historia alternativa o alohistoria, la historia apócrifa, la historia animal o xenohistoria, la historia alegórica, la historia paralela.

El doble aspecto documental y artístico de la escritura de la historia ha quedado prácticamente oculto por la insistencia en el carácter científico de la disciplina y su expulsión subsiguiente del canon literario desde el siglo XIX. El cultivo de la historiografía ficticia o imaginaria (fictohistoria) surgió entonces como un modo de salvar la literariedad de la historia, en su calidad de género formal, mediante el uso del discurso historiográfico como procedimiento retórico para conseguir un efecto de historicidad en textos que son, no obstante, claramente ficticios, y que tienen a menudo un carácter satírico o admonitorio. Esto no está reñido con el hecho de que la mayoría manifieste en primer lugar una reflexión sobre el devenir de la humanidad, es decir, sobre la Historia. Los ejemplos de este género son relativamente abundantes y se pueden clasificar en varias categorías temáticas. Esta primera parte del estudio se centra en la historia alternativa o alohistoria, la historia apócrifa, la historia animal o xenohistoria, la historia alegórica y la historia paralela.
\end{abstract}

Palabras clave: discurso historiográfico, ficcionalidad, prospectiva, literaturas románicas.

[Recibido, junio 2012; aprobado, diciembre 2012]

Fictional or Imaginary History in Romance Literatures since the $19^{\text {th }}$ Century: an Attempt at a Typology and Overview of an Unsuspected Formal Genre (I)

\begin{abstract}
The double dimension - documentary and artistic — of historical writing has been virtually overshadowed by the emphasis on the scientific nature of the discipline and its subsequent expulsion from the literary canon from the nineteenth century onwards. Fictional or imaginary history then appeared as a way to safeguard the literariness of history as a formal gender, using the rhetorical discourse of historiography to achieve an effect of historicity in texts that are, however, clearly fictional, and which often have a satirical or cautionary intent. Nevertheless, most of them convey first of all considerations on the evolution of humanity, and on its History. Examples of this genre are relatively abundant and can be classified into several thematic types. This first part of this study focuses on the alternate history, the apocryphal history, the animal history, the allegorical history, and the parallel history.
\end{abstract}

Keywords: historiographical discourse, fictionality, future history, Romance literatures. 
Hasta la historiografía decimonónica no se sintió demasiado la necesidad de distinguir literariamente relación histórica y relato ficticio. Ambas modalidades narrativas tenían objetos diferentes, pues la primera pretendía dar noticia de unos hechos que habrían ocurrido realmente, mientras que la segunda era fruto de la imaginación. Sin embargo, a las dos se les aplicaban unos procedimientos retóricos en gran medida comunes, de modo que la ornamentación estilística desempeñaba una función fundamental en ambos tipos de discurso. El panorama empezó a alterarse de forma cada vez más radical con el advenimiento de la historiografía científica en el siglo XIX, especialmente desde el triunfo del Positivismo ${ }^{1}$. El estudio de la Historia pasó a basarse en la investigación exhaustiva de las fuentes documentales, previamente a la construcción de un relato cuyo carácter fidedigno y ajustado en lo posible a la realidad del pasado se fundaba en el principio de falsabilidad, gracias a su dependencia de una documentación comprobable (y ampliable), frente a la arbitrariedad intrínseca y no susceptible de refutación empírica de los enunciados ficticios constitutivos del cuento y la novela. Al mismo tiempo, el ornato estilístico fue cediendo paso, en la historia, a una obsesión por la verificabilidad, que se tradujo, por una parte, en la presencia invasiva de los documentos en el cuerpo textual, y, por otra, en la desconfianza general hacia la dimensión retórica y literaria de la prosa historiográfica ${ }^{2}$.

Este fenómeno, aunado con frecuencia a una rebaja de lo propiamente narrativo, tuvo como consecuencia su práctica salida del universo de la literatura a efectos de canon. La función poética, que entendemos como el resultado de una serie de procedimientos retóricos dirigidos a señalar y sostener estéticamente la forma lingüística de un texto con independencia de su contenido, no ha desaparecido en muchos historiadores modernos, algunos de los cuales pueden considerarse modelos de estilo, pero parece

1 «Des modèles de représentation (biologiques, sociologiques, évolutionnistes, etc.) comme des modèles de validation (l'appareil de notes, le désengagement énonciatif de l'auteur, l'examen critique des discours rapportés, etc.) rendent visibles ou accentuent les distinctions entre récit littéraire-fictionnel et récit rationnelréférentiel [...]. Romans historiques et histoires, récit de voyage et géographies sérieuses, etc., toutes ces formes siamoises qui partageaient jusqu'alors un système circulataire commun, l'art rhétorique, se voient séparées par la chirurgie positiviste » (Gefen 2002: 5).

2 Otro indicio de la separación entre historiografía y literatura en el siglo XIX es la práctica desaparición de las crónicas en verso que, desde la Edad Media, se habían distinguido de la épica de tema histórico por su carácter de testimonio de hechos acaecidos realmente, frente a la inclusión programática de elementos fabulosos, sobre todo de índole mitológica o sobrenatural, en la épica. La historiografía en verso deja prácticamente de escribirse en la época romántica, aunque su lugar en la ecología literaria lo suelen ocupar las baladas históricas de tendencia más o menos nacionalista y equivalentes a la novela histórica también en auge desde aquel momento. Sin embargo, estas baladas se escriben y se leen en el marco de la poesía épica y no de la historia, aunque su contenido pueda ajustarse, paradójicamente, a las normas historiográficas al adoptar un discurso objetivo y centrado exclusivamente en los hechos de interés para la colectividad en su conjunto, sin personajes individualizados en su dimensión privada, entre otras características a las que aludiremos más abajo. Esta épica tan cercana funcionalmente a la narración de la historia pudo aplicarse ocasionalmente a materiales fantásticos, produciéndose así obras híbridas en la que el verso y la retórica de la epopeya se aplican a un planteamiento de historiografía imaginaria en poemas tales como Les Fossiles (1854), de Louis Bouilhet (una historia de la Tierra y de la humanidad hasta el futuro); La Révolte des fleurs (1874), de Sully Prudhomme (un episodio de la historia de las flores vistas como especies inteligentes y dotadas de una vida social e histórica propia), o historias versificadas de la Atlántida como Atlantis sau epoca de aur (1929), de Cleant Spirescu, a los que se pueden añadir los númerosos pasajes en verso de Star ou $\Psi$ de Cassiopée (1854), de Charlemagne-Ischir Defontenay. El relativo prosaísmo de estos poemas narrativos, que parece a menudo deliberado, tiende también a emparentarlos con la historia como género literario, aunque su escritura y su intención épicas impide considerarlos continuadores de las antiguas crónicas rimadas. 
indudable que la historia contemporánea rara vez recibe atención como objeto literario, susceptible de un estudio filológico y estilístico tanto como un poema o una novela. Mientras tanto, en el ámbito de la historiografía, las semejanzas entre la narración ficticia y la histórica son cruciales, por ejemplo, para los narrativistas, especialmente los postmodernos. Estos relativizan las fronteras entre ambos tipos de narración, aunque tampoco suelen poner en duda el hecho de que el historiador no es libre. Según declara un defensor de la capacidad futurológica de los historiadores formados profesionalmente («Historians are well equipped to write imaginative, disciplined, and realistic histories of the future» [los historiadores están bien preparados para escribir historias del futuro imaginativas, disciplinadas y realistas]; Staley 2002: 89) al comentar la postura de uno de estos historiadores-futurólogos ${ }^{3}$, «postmodernist literary theory confirmed what he had long believed about history writing: that history is a story, and the historian is a type of storyteller» [la teoría literaria postmoderna ha confirmado lo que él creía desde hacía tiempo acerca de la escritura de la historia: que la historia es una historia y que el historiador es un tipo de narrador de historias] (82), aunque introduce una salvedad esencial (82):

It is true that both scenario-building and history are forms of storytelling. But while historians are indeed storytellers, we write particular types of disciplined stories. Unlike fiction writers who enjoy many more degrees of narrative freedom, historians must adhere to specific methods that limit the types of stories we are permitted to write.

El historiador sigue debiendo un respeto a una verdad documental que se manifiesta mediante unas marcas de historicidad que guían al lector y le indican que no se trata de una recreación imaginaria ni de una novela histórica. Por ejemplo (Leduc 1999: 182):

[E]xplications sur les conditions de la recherche, citations, paratexte (notes, bibliographie, etc.). Elles indiquent que la narration ne se suffit à elle-même, qu'elle n'est pas autoréférentielle et elles attestent l'intention de se soumettre à un contrôle.

Esta búsqueda de la verdad documentada del pasado salvaría la historia genuina del relativismo escéptico de aquellos que ven en ella sobre todo una construcción lingüística y, como tal, tan artificial como cualquier otro tipo de relato. Se ha afirmado así en medios textualistas que la historiografía está constituida por una serie de textos culturales mediados por el presente, en su calidad de actividad de producción de signos, entre otras similares (la misma novela histórica, por ejemplo). Desde este punto de vista, sus marcas de historicidad corresponderían a un intento ilusorio de semiosis científica, ya que se trataría de «un genre de discours dont l'imposant appareil (références, sources, bibliographie, documents iconiques) a peut-être pour fonction principale de nous persuader de la démarche scientifique plutôt que d'étayer una démonstration rigoureuse qui irait au-delà de la seule vraisemblance» (Francœur 1988-1989: 189). Así pues, una historia objetiva, ficticia o no, sería una quimera, pues «ce que [...] la sémiotique entend dire des textes historiques, roman ou discours, c'est que les faits passés qui nous sont communiqués sont des objets construits par l'introduction d'un sens actuel dans l'objet ancien» (190).

3 «Scholars who are in the habit of telling stories about the past are especially well positioned to tell stories about the future» (Wagar 1998: 367). 
Estas posturas opuestas marcan los contornos de una polémica implícita en torno a la categorización de la historiografía, aparentemente con la intención de fundamentar o, por el contrario, refutar el estatuto científico de dicha disciplina. Esta disputa suele dejar de lado, sin embargo, numerosas obras de historia ${ }^{4}$ imaginaria, cuyo estudio evidenciaría que la forma de discurso historiográfico no es pertinente para afirmar o negar su verdad histórica, cuya determinación depende de otros criterios, mientras que sí lo sería para sugerir la literariedad potencial de un texto historiográfico dado, para lo cual resulta indiferente si lo referido es real o no, puesto que la perspectiva adoptada por el crítico literario para valorar dicho texto es completamente distinta a la del historiador que juzga su veracidad. Desde este punto de vista, resulta perfectamente factible afrontar una paradójica historicidad ficticia como objeto legítimo de estudio, dejando en suspenso los criterios de verificabilidad que condenarían a este tipo de obras como fraudes mentirosos, de los que tantos supuestos historiadores se hacen culpables con intenciones normalmente de orden espuriamente político, al intentar hacer pasar por verdad lo que no es sino manipulación. En cambio, lo que llamamos fictohistoria ${ }^{5}$, en su calidad de modalidad artística, no es engañosa, pues los lectores saben (o deberían saber) que no pueden ser reales una historia contrafáctica, del futuro, de una especie no humana, de un territorio fantástico o fundada en una documentación inexistente. Este género trata más bien de sacar partido de las marcas lingüísticas de la historicidad, cuya existencia reconocen hasta los historiadores más opuestos a las doctrinas textualistas ${ }^{6}$, para ocupar un campo literario que había dejado prácticamente libre la adopción del discurso científico por parte de la historiografía. De este modo, los procesos expuestos en la fictohistoria se perciben intrínsecamente como imaginarios, aunque los autores multiplican los indicios de veridicidad en su aprovechamiento creativo de un modelo narrativo secular, pero que parecía marginado en la escritura historiográfica moderna. Así se pudo salvar la historia como género literario y ha podido subsistir hasta hoy, tal vez porque se

\footnotetext{
4 En las lenguas románicas, incluida la española, no existe la útil distinción inglesa entre una historia en el sentido de relato de imaginación (story) y la relación en forma narrativa y aparentemente verídica de una sucesión de acontecimientos ocurridos realmente a lo largo del tiempo (history). En el presente ensayo utilizamos el término de «historia» exclusivamente para designar el segundo de los significados señalados («history» en inglés), ligándolo a la tradición de «historia» como género literario, como discurso con una construcción retórica determinada. En cuanto a la historiografía, el vocablo designa sobre todo el arte de escribir la historia, aunque a veces se utiliza como sinónimo cercano de la historia tal como se ha definido arriba, especialmente cuando se trata de conseguir una mayor especificación, dada la extensión semántica actual de «historia» en el habla común; por lo demás, «[1]’histoire est intrinsiquement historio-graphie, ou, pour le dire d'une façón délibérément provocante, un artifice littéraire» (Ricœur 1991: 287). El referente real, esto es, el curso de los acontecimientos en el pasado, lo denominaremos «Historia»: «Histoire et histoire, la majuscule pour le réel, le passé vécu par des hommes de chair et de sang, la minuscule pour l'humble image qui s'efforce d'en recomposer le labeur de l'historien» (Marrou 1975: 36).

5 Adoptamos este neologismo acuñado por Carlos Barral, para quien «la fictohistoria consiste en imaginar un episodio o un período histórico que no ha tenido lugar, a partir, por ejemplo, de la modificación de un acontecimiento determinante» (1980: 7). Aunque se refiera más bien a lo que se suele denominar ucronía y no distinga entre textos ficticios novelísticos e historiográficos, su definición es aplicable mutatis mutandis al género formal que aquí se examina.

6 Segun Pomian (1999: 402-403), todas las escrituras de la historia deben «comporter des marques d'historicité: des tournures verbales ou des signes graphiques ou iconiques qui renvoient aux preuves des affirmations énoncées dans le texte et qui doivent permettre aux lecteurs d'y accéder. [...] Mais il y a aussi des marques d'historicité internes à la langue: l'historien a besoin d'une rhétorique particulière». Es precisamente esta retórica la que permite a la fictohistoria crear la ilusión de que las supuestas fuentes documentales utilizadas existen y que en ellas se basa la obra. La historiografía no ficcional simplemente remite a fuentes comprobables, pero dicha comprobación implica la salida del espacio textual.
} 
ha podido ver en ella un modo de expresar literariamente visiones especulativas de la Historia.

Por otra parte, el escritor se ve exonerado en la fictohistoria de la obligación novelística de manejar unos actantes individualizados. Estos habrían impuesto una perspectiva demasiado limitada a lo que se desea presentar como la pintura de unos fenómenos colectivos, para que el propósito admonitorio o satírico se pueda aplicar a toda la humanidad o, al menos, a una sociedad entera, con todas las ventajas de lo ilusoriamente real: en contraste con el discurso maravilloso, la presencia de marcas de historicidad aporta un suplemento de realidad a lo representado, que se constituye así en un mundo imaginario, aunque verosímil y, en general, creado conforme a las exigencias de la razón. Esto acentúa, a su vez, la eficacia del discurso como análisis e hipótesis sobre el curso de la Historia, en torno a unas tendencias cambiantes estructuralmente ante las cuales el individuo no parece pesar demasiado, y de ahí también que la fictohistoria tienda a adoptar la colectividad como protagonista ${ }^{7}$. Los fictohistoriadores no se ocupan

7 En consecuencia, no se considera aquí el género emparentado de la fictobiografia, constituido por las biografías apócrifas de personas destacadas normalmente por su actividad pública (religiosa, artística, literaria, etc.), en las que se combinan, según el modelo de la biografía historiográfica (incluida su documentación de apoyo), la narración de apariencia objetiva de su trayectoria y la descripción factual de su personalidad y labor, tales como las vidas de los escritores imaginarios que sirven de prólogo a las ediciones de sus obras supuestas «Notice sur Clara Gazul» (Théâtre de Clara Gazul comédienne espagnole, 1825) y «Notice sur Hyacinthe Maglanovich» (La Guzla ou choix de poésies illyriques recueillies dans la Dalmatie, la Bosnie, la Croatie et l'Herzégowine, 1827), de Prosper Mérimée; «Vie de Joseph Delorme» (Vie, poésies et pensées de Joseph Delorme, 1829), de Charles-Augustin Sainte-Beuve; «Vie de Bilitis» (Les Chansons de Bilitis, 1895), de Pierre Louÿs, o «Tsing Pann Yang, la vie et l'œuvre» (La Terrasse des désespoirs, 1943), de Yves Gandon, entre otras «supercheries littéraires» [supercherías literarias] francesas estudiadas por Jeandillou (2001). También son fictobiografías las Noticias biográficas acerca del Excmo. Sr. Marqués del Mantillo (1889), de Silverio Lanza (Juan Bautista Amorós), en que se historia de forma muy personal el ascenso político del protagonista en un Estado imaginario que refleja alegóricamente el funcionamiento de las monarquías constitucionales seudoliberales coetáneas; la vida y doctrina del teólogo imaginario «Sinesio de Rodas» (Confabulario, 1952), de Juan José Arreola; la «biografía» de Jusep Torres Campalans (1958), de Max Aub, esto es, la parte de este libro que cuenta la vida de ese pintor vanguardista inventado, presentada de manera tan verosímil que se llegó a tomar por verdadera. A estas obras se pueden sumar, por ejemplo, parodias como «Filomena Ustrell (1916-1962)» (Invasió subtil $i$ altres contes, 1978), vida de la madre de un idolatrado futbolista imaginario escrita por Pere Calders, y pastiches, a menudo burlescos, de las biografías académicas, tales como «Vie et travaux du R.P. Cruchard par le R.P. Cerpet de la Société de Jésus», de Gustave Flaubert, terminada en 1873 y publicada en 1943; «Ludwig Schnorr ou la marche de l'histoire» (1958; Les Dupes, 1959), de Jean Dutourd; "A modo de biografia y más», que sirve de introducción crítica a las apócrifas Revelaciones de la Madre Margarita Amable del Divino Niño del Sí (1970), de Rafael Pérez Estrada; «Une amitié scientifique et littéraire : Léon Burp et Marcel Gotlib suivi de Considérations nouvelles sur la vie et l'œuvre de Romuald Saint-Sohaint» (1980; Cantatrix sopranica L. et autres écrits scientifiques, 1991), de Georges Perec; «En el centenari de Valerià Cabrera i Prats» (1981; reescrita con el título de «En homenatge a Valerià Cabrera i Prats» y recogida en El mirall venecià, 2008), de A. Munné-Jordà, o «Laoché Hernández, artesano de la imaginación» (El carpintero y la lluvia, 2010), de Rodolfo Martínez. En cambio, parecen serias «Noticia de Gabriel Zapata» (La República de Mónaco, 2000), de Marcos Ricardo Barnatán, y, en mayor medida, las alobiografías o biografías ucrónicas Les Trois Rimbaud (1986), de Dominique Noguez, y H. P. L. (1890-1991) (1995), de Roland C. Wagner, en que Arthur Rimbaud y H. P. Lovecraft, respectivamente, siguen escribiendo hasta una edad más avanzada. Destaca también 3012: l'anno del profeta (1995), de Sebastiano Vassalli, la hagiografía o evangelio de Antalo, un profeta del futuro en un mundo cuya evolución describe el autor al modo de la historia prospectiva. Asimismo, consideramos fictobiografías los textos que narran la vida de un personaje ficticio de una obra clásica como si fuera real, ajustándose al discurso historiográfico, entre las que se cuentan recreaciones de figuras de Martín Fierro (1872-1879), de José Hernández, tales como Vida de Martín Fierro, el gaucho ejemplar (1934), de José María Salaverría, y «Biografía de Tadeo Isidoro Cruz 
tanto de las personas como de las muchedumbres ${ }^{8}$. El personaje individualizado es, de existir, un actante que representa o determina un proceso histórico, pero no se le considera en su dimensión privada, en diálogo con otros individuos, ni tampoco se presenta su interioridad más que como hipótesis razonada ${ }^{9}$. Esto distingue fundamentalmente la fictohistoria de la novela o el relato en general, géneros narrativos de los que se diferencia también por una serie de criterios formales que permiten reconocer la fictohistoria a primera vista. El criterio distintivo crucial es, de hecho, el retórico: una fictohistoria lo es por presentar los hechos mediante un discurso determinado, el historiográfico, entendido este como «a verbal structure en the form of a narrative prose discourse that purports to be a model, or icon, of past structures and processes en the interest of explaining what they were by representing them» (White 1975: 2) con unas marcas formales definitorias determinadas, a saber ${ }^{10}$ : la ausencia de diálogos, salvo la transcripción de intervenciones o debates considerados decisivos en un proceso histórico, sobre todo en

(1829-1874)» (1944; El aleph, 1949), de Jorge Luis Borges, o las de personajes literarios populares como el náufrago por excelencia en «La famosa noche de Robinson Crusoe en Pamplona» (1929), de Rafael Sánchez Mazas, y «El maestro de la soledad» (El retablo de Maese Pedro, 1973, y Más arriba del reino, 1980), de Pedro Gómez Valderrama, por ejemplo. Por último, conviene recordar las semblanzas de personas o personalidades inexistentes, las cuales suelen presentar también un matiz irónico, como las recogidas en La sinagoga degli iconoclasti (1972), de Juan Rodolfo Wilcock; Os escuros soños de Clío (1979), de Carlos Casares, o La literatura nazi en América (1996), de Roberto Bolaño, así como varias de «Las figuras» e «Historias apócrifas» de Galería de espejos sin fondo (1963), Rosas, diablos y sonrisas (1965) y Nicéforas y el grifo (1968), así como sus versiones en catalán publicadas en las Històries apòcrifes (1974) y otros libros, todos de Juan/Joan Perucho. También se pueden añadir las minibiografías de los autores imaginarios de los textos de antologías apócrifas como Vidas improbables (1995/2009), de Felipe Benítez Reyes; Pantasmes, mundos, laberintos (1996), de Xuan Bello; 26,5 auteurs qui n'existent pas mais qu'il faut absolument avoir lus (2008), de Samir Bouadi y Agathe Colombier-Hochberg, o las «Introduções» de Os Anos de Ouro da Pulp Fiction Portuguesa (2011), de Luís Filipe Silva.

8 «[L]'histoire met à la place du sujet de l'action des entités anonymes au sens propre du mot» (Ricœur 1991: 314). Por lo demás, «rien dans la notion de personnage, entendu au sens de celui qui fait l'action, n'exige que celui-ci soit un individu» [en la noción de personaje, entendido en el sentido de quien hace la acción, nada exige que este sea un individuo] (346-347).

9 Según Cohn (1999: 121-122), «even when historical narration concerns individual figures and singulative moments [...] it draws on a language of nescience, of speculation, conjecture, and induction (based on referential documentation) that is virtually unknown in fictional scenes of novels (including historical novels) cast in third-person form». Cohn persigue distinguir así con claridad la historia de la novela, sin tener en cuenta que basta con que esa «referential documentation» [documentación de referencia], implícita o explícita, sea imaginaria para que un texto ficticio pueda ser plenamente histórico, y no novelístico, formalmente. Aunque reconozca que « $[\mathrm{t}]$ he fictional history of an other-worldly or future-worldly society, for example, or, for that matter, an "apochryphal history" of our own world might be effectively told by a narrator posing as a historian» [un narrador que se hiciera pasar por historiador podría contar efectivamente la historia ficticia de una sociedad de otro mundo o de un mundo futuro, por ejemplo, o, incluso, una «historia apócrifa» de nuestro propio mundo] (120), sigue insistiendo en unas marcas de ficcionalidad intratextuales que sí hay en la novela (o el drama), pero no en otras formas de ficción como la que nos ocupa, cuya existencia misma sugiere que la ficcionalidad de una narración puede depender exclusivamente de indicios no textuales, en especial de la imposibilidad de referenciar la materia de la fictohistoria, por ser esa materia puramente imaginaria. En cambio, si nos atenemos exclusivamente a su discurso común, la fictohistoria y la historia cientifica pertenecen al mismo (macro)género, la historia.

10 Las características enumeradas a continuación no son exhaustivas y solo persiguen indicar algunas características fácilmente perceptibles para cualquier lector, a efectos del fácil reconocimiento de cualquier fictohistoria. Un análisis discursivo más pormenorizado y técnico, con el mismo enfoque que adoptamos, figura en un trabajo que se esfuerza por probar que Herrumbrosas lanzas (1983-2009), de Juan Benet, «no solo versa sobre acontecimientos históricos, también y esencialmente se finge Historia, texto historiográfico» (Martínez Duró 2007: 87), al que remitimos también para el mejor entendimiento de dicha obra benetiana. Esta es, en efecto, fictohistórica en su mayoría, salvo su segunda parte, que recurre más bien al discurso novelístico. 
asambleas o reuniones oficiales, ante testigos; la escasez de descripciones de paisajes y objetos concretos; el predominio absoluto de los tiempos verbales del pretérito (excepto en los anales o textos en formato cronológico, que están normalmente en presente de indicativo, el cual puede aparecer ocasionalmente en otros textos, en su calidad de presente histórico); la narración heterodiegética, en tercera persona ${ }^{11}$, con la omnisciencia

11 Cabría postular, no obstante, la existencia de una fictohistoria narrada en primera persona al modo del género más claramente historiográfico de las escrituras del yo, las memorias. Estas se pueden entender como «la reconfiguration narrative du mémorable d'une vie, transmise dans le souci de servir à la connaissance des mobiles qui guident les hommes engagés dans le cours de l'Histoire» (Jeannelle 2008: 392), presentada esta con postulada objetividad desde la perspectiva de una persona que se expresa en su calidad de agente o testigo de la Historia y, en consecuencia, como figura pública, a diferencia del yo privado de la autobiografía o del diario íntimo. Lo enunciado se focaliza, pues, en los acontecimientos externos al yo, de manera que la narración homodiegética es, a la vez, autodiegética (por la perspectiva en primera persona, incluida la mostración de la conciencia del narrador) y homodiegética testimonial, por lo que también consideramos como pertenecientes al género los diarios en que una persona no consigna su intimidad, sino su actuación y su testimonio como fuente histórica para el futuro, como los diarios de campaña o exploración, de acuerdo con la útil distinción rumana entre jurnal (diario íntimo) e însemnări (anotaciones memorialísticas). Si la voz historiadora en primera persona se atribuye a un personaje imaginario en una situación también claramente imaginaria (excluyendo, pues, las seudomemorias fraudulentas que pretenden hacerse pasar por reales), nos encontraríamos claramente ante fictomemorias, como las satíricas La conquista del reino de Maya por el último conquistador español Pío Cid (1897), de Ángel Ganivet, en que el protagonista procede a una relación objetiva de sus actos en aquel fantástico reino africano en forma impecablemente historiográfica, incluidos los títulos descriptivos sintéticos de los capítulos frecuentes en la historia profesional decimonónica. Las relaciones de exploraciones geográficas de los grandes descubridores-escritores del pasado, desde Cristóbal Colón hasta Robert Falcon Scott, también han servido de modelo para las fictomemorias. En las de esta clase es relativamente común que el autor haga pasar la obra como la edición moderna del testimonio de aspecto oficial de un explorador que cuenta lo que ha vivido y presenciado, como ocurre en Paraules d'Opoton el Vell (1968; en castellano, en la versión del propio autor, Palabras de Opoton el Viejo: Crónica mexicana del siglo $X V I, 1992)$, de Avel·lí Artís-Gener, en que el jefe de una expedición azteca cuenta su descubrimiento de la Península Ibérica, o en la «Crónica de Isaac bar Nathan, mensajero de Hasdai ibn Shaprut, primer ministro del califa de Córdoba, ante José, rey de los kázaros» (El horóscopo de las infantas, 1988, y La República de Mónaco, 2000), de Marcos Ricardo Barnatán, que imita hábilmente los libros hebreos medievales de viajes, así como en informes de descubrimientos de poblaciones de extrañas costumbres como «Gzwrrawtzicxm» (Un crim abstracte o el jardiner assassinat, 1965), de Nicolau Maria Rubió i Tudurí, y «Evolução» (2006), de Miguel Vale de Almeida. Un paratexto semejante al de las memorias de viajeros ficticios sirve de introducción a El testimonio de Yarfoz (1986), de Rafael Sánchez Ferlosio, libro que se presenta como las memorias apócrifas del amigo del príncipe exiliado de unos pueblos imaginarios de la Iberia prerromana, que un historiador de esos pueblos habría publicado siglos después, como apéndice documental, en la imaginaria Historia de las guerras barcialeas. La presencia en estas obras de marcas historiográficas paratextuales destinadas a hacer creer en la veridicidad del documento se suma a la utilización, determinante desde el punto de vista de la adscripción genérica, de una escritura predominantemente historiográfica en las fictomemorias, lo que las distingue de las memorias también ficticias, aunque clasificables más bien en la narrativa histórica por adoptar una forma más bien novelística, como Mémoires d'Hadrien (1951), de Marguerite Yourcenar (Marguerite Cleenewerck de Crayencour), o Maluco, la novela de los descubridores (1989), de Napoleón Baccino Ponce de León, aparte del hecho de carecer estas últimas de la dimensión especulativa o fantástica frecuente en las fictomemorias propiamente dichas. No obstante, la distinción discursiva entre las fictomemorias y otras narraciones especulativas análogas narradas en primera persona exigiría un análisis retórico más detenido que no podemos acometer aquí, aunque se puede decir que las últimas recurren ampliamente al diálogo y a otros signos novelísticos generalmente marginales en las fictomemorias, cuyo discurso tiende a acercarse al historiográfico y cuyos temas tienden a hacer hincapié en la dimensión colectiva y sociohistórica del testimonio inventado, como ocurre, por ejemplo, en las seudomemorias Souvenirs de la marquise de Créquy, 1710 à 1802 (1834-1836), escritas por Maurice Cousin, conde de Courchamps. Esto distingue también esencialmente las fictomemorias de otro género del yo, la autobiografía, en el que lo esencial es el recuerdo y la confesión de una vida en su dimensión sobre todo privada, lo que las confiere un aire subjetivo y personal distinto al objetivismo postulado de las (ficto)memorias. 
del narrador limitada a las acciones documentadas o perceptibles desde fuera ${ }^{12}$; «the massive prevalence of summary over scene» (Cohn 1999: 121); el estilo objetivizante y de sobrio aire académico, y la presencia frecuente de paratextos documentales (bibliografía, notas, mapas, transcripción de documentos preexistentes ajenos a la voz enunciadora, etc.) a fin de crear una ilusión de referencialidad ${ }^{13}$, entre otros rasgos discursivos distintivos de la historiografía, mediante los cuales la historia parece contarse sola, asertivamente $^{14}$. En ocasiones, el fictohistoriador añade alguna indicación paratextual del carácter de supuesto tratado histórico de la obra, como ocurre, por ejemplo, en la historia prospectiva «Un texto escolar sobre $\mathrm{OH}$ » (La guerra, el mar y otros excesos, 1966), de Fernando Quiñones, o en la alegórica «Historia de la fragua (para la escuela media)» (1988), de Fernando U. Segovia (¿Angélica Gorodischer?), cuyos títulos indican claramente de qué tipo de manuales se trata. Sin embargo, esta clase de alusiones no es estrictamente necesaria para la clasificación como fictohistoria de una obra, si esta presenta con claridad sus prácticas discursivas propias en el conjunto del texto ${ }^{15}$, de

12 Entre la novela (y el relato o el cuento) y la historia, «les différences les plus nettes semblent affecter essentiellement les allures modales les plus étroitement liées à l'opposition entre le savoir relatif, indirect et partiel de l'historien et l'omniscience élastique dont jouit par définition celui qui invente ce qu'il raconte» (Genette 2004: 166).

13 «No solo hay ausencia de subjetividad, sino que se produce un procedimiento de objetivación: aquello de lo que el texto habla, los "objetos", se dotan de existencia mediante la apelación a documentos, decisiones, disposiciones, [por los] que a su vez, encuadrados en una organización temporal y espacial, se produce el fenómeno de referencialización» (Lozano 1987: 189).

14 Barthes caracteriza el discurso histórico en estos términos (1984: 168): «Il s'agit du cas où l'énonciateur entend "s'absenter" de son discours et où il y a, par conséquent, carence systématique de tout signe renvoyant à l'émetteur du message historique: l'histoire semble se raconter tout seule. [...] En fait, dans ce cas, l'énonçant annule sa personne passionnelle, mais lui substitue une autre personne, la personne "objective" : le sujet subsiste dans sa plénitude, mais comme sujet objectif». Y más adelante (171): «[L]e statut du discours historique est uniformement assertif, constatif; le fait historique est lié linguistiquement à un privilège d'être: on raconte ce qui a été, non ce qui n'a pas été ou ce qui a été douteux». Esta forma de enunciación es la misma de la fictohistoria.

15 Como el presente estudio tiene por objeto presentar el género de la fictohistoria y contribuir a despejar las confusiones existentes con las ucronías o historias del futuro novelescas, no consideraremos, en general, las obras que presentan pasajes fictohistóricos de mayor o menor extensión, ni siquiera cuando estos constituyen gran parte del texto, tal como ocurre, por ejemplo, en la citada Herrumbrosas lanzas, de Juan Benet, o en las conmovedoras y terribles historias prospectivas «Les Géants chauves» (1871/1892), de Gabriel Tarde, y «La Terreur future» (Cœur double, 1891), de Marcel Schwob, o en la sarcástica «Surhommes» (La Boîte aux marionnettes, 1930), de Henri-Jacques Proumen, así como en las historias alternativas «Si Louis XVI...: un essai d'histoire hypothétique» (Mes songes que voici, 1932), de André Maurois, que presenta un curioso marco teológico (todas las historias son posibles en Dios, el Supremo Cronista); «Si Evita hubiera vivido» (1990), de Daniel Barbieri (Daniel Croci), y, sobre todo, Contro-passato prossimo: un 'ipotesi retrospettiva (1975), de Guido Morselli, en la que este «esprime il suo pensiero antistoricistico e antifatalistico, la critica alle idee correnti, il richiamo del senso di responsabilità» (Fasano 1998: 102). En esta historia alternativa profundamente moral, en que los imperios centrales vencen en la Gran Guerra y esto facilita una unificación europea más temprana, «ist noch auf eine narrative Besonderheit von Contro-passato prossimo hinzuweisen, die darin besteht, dass Morselli den Text wie ein Roman — mit fiktionalem Vordergrund und kontrafaktischem Hintergrund - beginnen läßt, ihn dann aber als ukronische Chronik weiterführt. Hieraus resultiert in erzähhltechnischer Hinsicht ein Bruch, denn die narrative Perspektive des ersten Teils, in dem der Autor die Welt des fiktiven Majors von Allmen entwirft, wird erst zu Ende des Epilogs wieder aufgenommen. Er hat der Anschein, als habe Morselli aus einem ursprünglich geplanten von Allmen-Text die Rahmengeschichte einer (erst danach ausgearbeiteten) kontrafaktischen Chronik gemacht, ohne die Übergänge zwischen beiden Textuniversen hinreichend zu homogenisieren»" [se debe indicar otra peculiaridad narrativa de Contro-passato prossimo, consistente en que Morselli hace empezar el texto como una novela de ficción — con un primer plano ficticio y un fondo contrafáctico-, pero luego lo continúa en forma de crónica alohistórica. El resultado es una ruptura desde el punto de vista de la técnica narrativa, porque la perspectiva narrativa de la primera 
forma que se genera una impresión de factualidad coherente y completa, que es esencial en el género historiográfico ${ }^{16}$. Por otra parte, como la fictohistoria cuenta una historia, es decir, presenta unos acontecimientos determinados en su sucesión ${ }^{17}$ como si fueran algo pasado, se distingue claramente también de las obras futurológicas que, en forma ensayística, pretenden explicar al público presente lo que va a deparar el futuro, gracias al presunto conocimiento del porvenir obtenido por iluminación sobrenatural (en el caso de las profecías) o mediante la extrapolación de tendencias contemporáneas, como en la Futurología moderna. Solo las profecías y las predicciones futurológicas que adopten el discurso narrativo historiográfico reúnen las condiciones para considerarse fictohisto$\operatorname{rias}^{18}$.

parte, en que el autor crea el mundo del ficticio del comandante Von Allmen, solo se retoma al final del epílogo. Parece como si Morselli hubiera construido, a partir de un texto sobre Von Allmen planeado inicialmente, el marco histórico de una crónica contrafáctica compuesta solo posteriormente, sin haber homogeneizado lo suficiente las transiciones entre ambos universos textuales] (Rodiek 1997: 107-108). De hecho, esa segunda parte puede leerse como una historia alternativa completamente independiente $\mathrm{y}$, desde este punto de vista, Contro-passato prossimo es a la vez novela (el marco protagonizado por Von Allmen) y fictohistoria (su segunda parte, considerada como texto autónomo). Algo similar puede afirmarse de la utópica «História geral do planeta Marte», que constituye la parte central de la História Autêntica do Planeta Marte (1921), de Henri Montgolfier (José Nunes da Matta, o de «La república feliz de Maranchón», que es la relación de un experimento utópico en un pueblo alegórico de la meseta central española que se presenta como la reproducción de un obra leída por un personaje de Cutrelandia: La República de las Letras (2005), de José Elgarresta. 16 «L'historien s'adresse à un lecteur méfiant, qui attend de lui non seulement qu'il raconte, mais qu'il authentifie son récit» (Ricœur 1991: 313).

17 Desde el punto de vista retórico aquí adoptado, no consideramos lo que se podría denominar fictohistoria bruta o presentación de sucesos ficticios como históricos mediante la mera yuxtaposición de supuestos documentos, por mucho que estos presenten con toda la ilusión de la referencialidad, tal como ocurre, por ejemplo, en recopilaciones de documentos contrafácticos como «Seva: Historia de la primera invasión norteamericana de la isla de Puerto Rico ocurrida en mayo de 1898» (1983), de Luis López Nieves, o «Les Trouble-fête: Morceaux choisis de documents relatifs à la crise de la jonction du $\mathrm{XX}^{\mathrm{e}}$ et du $\mathrm{XXI}^{\mathrm{e}}$ siècle» (2008), de JeanPierre Laigle. Estos materiales documentales se ofrecen ahí en bruto, sin apenas elaboración discursiva historiográfica, mientras que en La renuncia del héroe Baltasar: Conferencias pronunciadas por Alejandro Cadalso en el Ateneo Puertorriqueño, del 4 al 10 de enero de 1938 (1974), de Edgardo Rodríguez Juliá, amplios paratextos historiográficos introducen las crónicas y documentos dieciochescos que el autor inventa, imitando hábilmente el lenguaje de la época, en su empresa de reescritura revisionista de la historia de Puerto Rico, de modo que «[1]a serie de tres conferencias dictadas por el historiógrafo Alejandro Cadalso, quien en el proceso de refutar documentos falaces y de rectificar sus propias afirmaciones anteriores sobre el papel histórico de Baltasar Montáñez, cita toda una serie de textos, incluyendo crónicas, cartas y diarios, resulta un recurso literario efectivo, un modo de forzar al lector a suspender la incredulidad» (Torres Caballero 2006: 31). En el mismo subgénero se pueden clasificar las obras que adoptan un modo de presentación análogo, consistente en la recopilación o reproducción de crónicas y reportajes periodísticos sobre algún suceso histórico imaginario, como «Journal du Déjeuner 15 septembre 1910», publicado como folleto aparte en Les Voyages de Kang-Hi ou Nouvelles lettres chinoises (1808), de Pierre-Marc-Gaston de Lévis; Le Rêve d'un irréconciliable (1869), de Paschal Grousset; la traducción de un número de un periódico alemán Comment Paris a été détruit en six heures le 20 avril 1924 (Le jour de Pâques) (1921), de [Louis] Baudry de Saunier; las breves «Efemérides» (Bibidibabidibu, 1970, y La Gioconda está triste y otras extrañas historias, 1976) de José Luis Garci; varias de las crónicas de la serie de Ucronías (1990), de Óscar de la Borbolla; las noticias seudotimorenses reproducidas en «A Natureza Humana» (1999), de Miguel Vale de Almeida, o las visiones de la ciudad futura a través de un número de periódico de 27 de enero de 2030 en Les Portes du possible (2005), de Benoît Peeters, con soberbias ilustraciones de François Schuiten.

18 Por ejemplo, pese a su título, la exitosa Une brève histoire de l'avenir (2006), de Jacques Attali, no es una fictohistoria, al estar escrita en los tiempos verbales del futuro de indicativo, con lo que la perspectiva siempre es la del presente, esto es, la del futurólogo y no la del (ficto)historiador que mira al pasado desde una hipotética perspectiva del porvenir. Por lo demás, el uso de los tiempos del futuro (y del condicional) constituye una marca propia del ensayo futurológico desde su primeras manifestaciones importantes, tales como Dans deux cent ans (1892), de Charles Richet. 
De esta manera, el aprovechamiento literario del discurso historiográfico ha podido salvar, por decirlo así, la historia como género literario indudable en un momento de crisis profunda del reconocimiento de su literariedad. Además, también ha resultado oportuno para expresar la nueva mirada totalizante que algunos escritores empezaron a dirigir hacia la sociedad sobre todo desde el siglo XIX, cuando se publicaron los primeros ejemplos notables de la fictohistoria moderna y se fueron creando sus modalidades principales, que nos limitaremos a evocar, y limitándonos a las literaturas románicas, con vistas a proponer un ensayo de tipología a partir de una serie de obras representativas de cada modalidad y a dar una pequeña idea de un panorama más rico de lo que se sospecha ${ }^{19}$, especialmente en el período de apogeo de la Modernidad. El género se vio favorecido entonces por el interés general por los movimientos de masas y las construcciones historiográficas tendentes a explicar el devenir humano de acuerdo con unas leyes universales, como el marxismo, el socialdarwinismo o la historia de las civilizaciones a la manera de Oswald Spengler o Arnold J. Toynbee. En cambio, la fictohistoria no parecer haber tenido el mismo predicamento desde 1945, aunque tampoco falten los ejemplos notables contemporáneos. Tal vez la erosión de la función social del escritorintelectual y el ascenso de una historiografía especializada más bien descriptiva y sociológica, en vez de narrativa, influyeron en este declive relativo (Pelegrín Campo 2010: 17):

\begin{abstract}
[A] partir de este momento [los decenios posteriores a la Segunda Guerra Mundial] las nuevas propuestas generalmente ya no adoptarán la forma de ensayos literarios -un formato que los acercaba peligrosamente a la narrativa ficcional-, sino que se plasmarán en análisis pormenorizados -al principio limitados al ámbito de la «nueva historia económica»-, apoyados en una metodología definida y con un objetivo claro, y se esforzarán por construir progresivamente un marco teórico conforme al que articular esta forma de investigación histórica.
\end{abstract}

En cambio, parece existir desde hace unos años una corriente de historiadores profesionales interesados en reapropiarse la fictohistoria como instrumento historiográfico especulativo, al menos en su apartado de historia contrafáctica, como sugieren compilaciones de ensayos como La historia de España que no pudo ser: doce prestigiosos historiadores explican lo que pudo haber sido y no fue (2007), editada por Joan Maria Thomàs' o las monumentales obras colectivas realizadas bajo la dirección de Jacques Spir, Frank Stora y Loïc Mahé tituladas 1940. Et si la France avait continué la guerre: Essai d'alternative historique (2010) y 1941-1942. Et si la France avait continué la guerre: Essai d'alternative historique (2012). No obstante, estas recopilaciones no suelen estudiarse como manifestaciones literarias, ni siquiera en los círculos de interesados en la ucronía ${ }^{20}$. Esta modalidad no ha escapado a la hegemonía abrumadora de la forma novelística en las últimas décadas, salvo contadas excepciones ${ }^{21}$, de manera que

19 Como se trata de caracterizar el género y de resumir su historia, y no tanto de analizar las distintas obras, preferimos en general reproducir lo que la crítica académica haya dicho de ellas, con lo que se puede delinear también, de forma indirecta, un pequeño panorama de su recepción en ese ámbito.

20 La ucronía se puede definir como sigue: «Sous-genre de la science-fiction traitant de la science "Histoire", l'uchronie décrit méthodiquement des univers crédibles et réalistes dans lesquels l'Histoire a suivi un cours différent de la nôtre à la suite d'un événement fondateur» (Henriet 2004: 333).

21 Por ejemplo, la recopilación rumana Motocentauri pe Acoperişul Lumii (1995) consta de una introducción esencial para la comprensión del universo ficticio del libro titulada «Scurtă istorie generală a lucrurilor», de 
se ha producido ahí una especie de invasión por la novela del posible espacio de la fictohistoria, tal como sugieren ciclos de «future history» [historia futura] como el célebre en medios fictocientíficos de Robert A. Heinlein, los cuales solo suelen tener de historiográfico el nombre, al tratarse de relatos más bien convencionales, esto es, de stories y no de histories ${ }^{22}$.

En el ámbito de la ucronía propiamente dicha, los repertorios y panoramas existentes (por ejemplo, Henriet 2004) ponen de manifiesto, de hecho, que este tipo de ficción se escribe desde hace tiempo sobre todo en forma de novela, aunque los ejemplos aducidos arriba sugieren que se ha mantenido hasta cierto punto la dicotomía formal entre ucronías fictohistóricas y ucronías novelísticas existente desde los inicios de este género temático. De hecho, la primera obra ucrónica extensa pertenece claramente por su discurso a una de las grandes ramas tipológicas de la fictohistoria, que podríamos denominar historia alternativa o alohistoria en sentido estricto. Napoléon et la conquête du monde. 1812 à 1832 . Histoire de la monarchie universelle (1836), de Louis Geoffroy, expone, con gran virtuosismo en cuanto a la técnica de la ucronía, cómo el emperador corso consigue evitar la derrota en las estepas rusas y crear un imperio planetario, cuya expansión describe el autor con devoción hagiográfica ${ }^{23}$ tan exagerada que no hay que descartar una posible lectura irónica por debajo de una «immagine di Napoleone propagata dell mitologia corrente, l'eco della divinizzazione operata dalle correnti mesianiche, impadronatesi ben presto del mito» (Minerva 1995: 216).

A continuación, Uchronie: l'Utopie dans l'histoire. Histoire de la civilisation européenne, telle qu'elle n'a pas été, telle qu'elle aurait pu être (1857/1876), de Charles Renouvier, presenta la evolución de Europa de haber conseguido el emperador Marco Aurelio prevenir el triunfo del cristianismo. Esta obra, que consagró el género ucrónico como expresión literaria de una concepción de «l'histoire comme hypothèse

Dănuț Ivănescu, Ionuț Bănuță y Caius Stancu. Esta adopta la forma de anales concisos que llegan hasta 2277, desde la derrota de los romanos a manos de los tracios hasta el abandono de la Tierra por sus habitantes, combinando así los dos grandes subgéneros a que aludiremos, historia alternativa e historia prospectiva, con un estilo muy postmoderno, pese a su estructura cronológica «închisă şi absolut liniară» [cerrada y absolutamente lineal» (Badea-Gheracostea 2010: 98). Existe algún otro ejemplo similar al rumano citado, tal como «Una cronología de Drímar» (Cabos sueltos, 2010), que sirve de marco referencial al universo futurista y cyberpunk de Drímar creado por Rodolfo Martínez.

22 Por esta razón, no consideramos fictohistoria Histoire de quatre ans, 1997-2001 (1903), de Daniel Halévy, cuya forma es la de una novela, pese a figurar en uno de los escasos acercamientos al género fictohistórico que nos ocupa, en su modalidad prospectiva o de historia futura, en el cual se puede leer «l'Histoire nécessite un ton purement narratif, sans éléments romanesques, sous peine de se rabaisser jusqu'à l'anecdote, qui ne se différencie pas, en anticipation, de la nouvelle ou du roman» (Versins 1972: 420a). A diferencia de esta obra de Halévy o del ciclo mencionado de Heinlein, la historia futura «nu trebuie confundată cu încercările unor autori de anticipații de a stabili cadrul temporal viitor al prozelor lor. Istoria viitoare [...] are toate aparențele unei lucrări de istorie, în care [...] sînt date descrieri seci ale evenimentelor, cu cifre şi date, fără contribuția discursului romanesc» (Antohi 2005: 142).

23 «Unter hagiographischem Schwulst leiden vor allem die letzten Kapitel, in denen das chronikalische Ordnungsprinzip zugunsten des Anekdotischen, Legendenhaften und Abenteuerlichen endgültig aufgegeben ist» [adolecen de hinchazón hagiográfica sobre todo los últimos capítulos, en los cuales el principio de orden cronístico da paso definitivamente a lo anecdótico, lo legendario y lo aventurero] (Rodiek 1997: 75). Esto no quiere decir que Geoffroy prescinda del discurso historiográfico en esos capítulos finales, sino más bien que refleja en ellos el gusto de algunos historiadores por lo anecdótico, especialmente al abordar la vida de grandes hombres (y mujeres). 
perpétuelle» [la historia como hipótesis perpetua] (Grillet 2000: 51), y que le dio nombre en varias lenguas, adopta una forma historiográfica impecable, pues, de hecho, «Uchronie ressemble trait pour trait à un livre d'histoire» [Ucronia se parece punto por punto a un libro de historia] (Grenier 1988: 179). Sin embargo, a diferencia de los de numerosos historiadores decimonónicos, lo narrativo se adelgaza y lo ensayístico pasa a primer plano, debido a la supeditación inestable de la ficción al propósito del autor de acometer una especie de filosofía de la historia. Esta intención autorial, sumada a la complejidad estructural de la obra, puede ir en detrimento de la legibilidad ${ }^{24} \mathrm{o}$, al menos, del valor literario del conjunto:

Il punto debole dell'ucronia di Renouvier risiede nel fatto che non si tratta di un divertissement letterario, per il quale non sarebbero adatte né la pesantezza dell'impostazione, né la prolissità del linguaggio. Nelle sue intenzioni la descrizione della storia come avrebbe potuto essere sembra costituire invece un tentativo di continuare il discorso filosofico con altri mezzi: ma ciò viene cercato en modo non lineare, spesso contraddittorio, naturalmente scivoloso per l'oggettiva difficoltà di tenere insieme una storia effettivamente accaduta e la trama delle propensioni immaginarie dell'autore. (De Boni 2003: 71)

Otras ucronías pioneras en forma historiográfica tienen un interés más local, incluso nacionalista, como la titulada «Cuatro siglos de buen gobierno» [1883; Por los espacios imaginarios (con escalas en la Tierra), 1885], de Nilo María Fabra, en la que «España, en lugar de ser una potencia venida a menos, ha sido faro y motor de la cultura, la sociedad y la tecnología de Europa y del mundo» (Merelo Solá 2009: 106). Ese interés limitado a la nación se prolonga en el siglo XX, a juzgar por ucronías de la Guerra Civil de 1936 en España como 1936-1976. Historia de la Segunda República Española (1976), de Víctor Alba, o de las convulsiones políticas y culturales de la primera república italiana («Una storia vera» [1979], de Umberto Eco, una curiosa e inusitada parodia lucianesca del género ucrónico recogida en Sette anni di desiderio [1986] e Il secondo diario minimo ${ }^{25}$ [1992]). En estas obras, la descripción de un país determinado o del mundo tal como habría sido de haber seguido la Historia otro curso puede cumplir una función de fantasía compensatoria, pero también sirve para rechazar el carácter determinista del devenir histórico, que se presenta a menudo en la ucronía como el resultado de una serie de microsucesos cuya alteración modifica el panorama sociopolítico entero. El cambio de uno de esos acontecimientos, por nimio que sea en apariencia, constituye un

24 El reconocimiento de la originalidad de Uchronie ha solido ir acompañada, quizá exageradamente, de graves reservas sobre su plasmación textual. Según uno de los mejores estudiosos del género, «Renouvier bedient sich zur Darbietung seiner - damals wie heute schwer lesbaren - Gegengeschichte einer doppelten Herausgeberfiktion» [Renouvier se sirve de la ficción de un doble editor para representar su contrahistoria tan difícil de leer entonces como ahora-] (Rodiek 1997: 77). La existencia de varios editores que comentan el núcleo histórico contrafáctico y relatan las vicisitudes del manuscrito introduce una complejidad desacostumbrada, que Renouvier no siempre sabe resolver, pero que aporta perspectivas distintas sobre el asunto. La estructura literaria de esta única ficción de Renouvier parece, de hecho, bastante experimental y ya se sabe que el experimentalismo literario no resulta demasiado aceptable para muchos lectores, aun cultos.

25 En este mismo volumen figura una anticipación política fictohistórica de 1991, «Italia 2000», que explota burlescamente el mismo tema en el contexto de la segunda república italiana. Otros ejemplos fictohistóricos contemporáneos de episodios de una historia contrafáctica de Italia son «Il grande volo dell’aquila bicipite (1859: Se il Granducato di Toscana non avesse aderito al Regno d'Italia)», de Enrico Rulli, y «Guerra lampo (1940: Se gli italiani avessero occupato Malta)», de Carlo De Risio, ambos de 2005. 
punto de divergencia que permite imaginar una Historia distinta, en la que la actuación del individuo puede tener tales consecuencias que se refuta tácitamente el postulado de buena parte de la historiografía científica moderna de la pertinencia exclusiva de las grandes corrientes sociales, económicas e ideológicas para explicar lo ocurrido en los distintos períodos. De esta manera, la fictohistoria parece adoptar el discurso historiográfico predominante para combatirlo a veces en su propio terreno, si bien los historiadores siempre pueden aducir que pergeñar una historia alternativa es poco más que un juego de salón intrascendente. Mucho más turbadora para ellos puede ser la fictohistoria que, al transcurrir en el pasado, parece difuminar las fronteras entre lo sucedido verdaderamente y lo ficticio.

En lo que podemos llamar historia apócrifa, cuyo modelo clásico lo constituye el mito de la Atlántida narrado en los diálogos platónicos Timeo (Tímaıos) y Critias (Koltias), el lector inocente podría caer en una confusión entre historia imaginaria e historia que se presenta como fiel a lo sucedido en nuestro mundo empírico si la ausencia de una cultura general mínima le impidiera darse cuenta, sin la ayuda de los paratextos explicativos, de que se trata de la historia de países inventados. Aparte de sus implicaciones éticas y metodológicas, esta confusión podría entenderse como el signo de una ficcionalidad triunfante (Guissard 1990: 9):

[D]ans la compétition, il y a possibilité d'une autre victoire de la fiction, totale cette fois, et contre laquelle l'historien n'a pas d'armes efficaces. Georges Duby a raconté ce qu'il avait ressenti en lisant La Gloire de l'Empire, de Jean d'Ormesson: “je voyais, ditil, le produit du métier que je fais et que j'aime, qui est de rêver sur des choses vraies, dénaturé, avec une extraordinaire habileté, parce que cette histoire parfaitement imaginaire était présentée bardée de tout l'appareil critique que l'historien professionnel se croit tenu de fournir. [...] J'ai eu l'impression vraiment de la profanation, de la transgression, de l'impur, éprouvant un sentiment de répulsion. [...] Ce livre a été pour moi un objet de dégoût. Je le tiens pour un bel objet, mais il me montrait mon métier travesti. C'était un roman revêtu des attributs de l'histoire".

Estas palabras sugieren hasta qué punto la fictohistoria puede suscitar rechazo entre los historiadores científicos, al menos cuando invade su coto vedado de las cosas pretéritas. Asimismo, puede servir de piedra de toque de la eficacia de esa obra maestra de la fictohistoria, publicada en 1971. Al historiar un imperio altomedieval europeo completamente imaginario y que «is not a disguised or allegorized picture of any actual political state» (Christensen 1990: 82), Jean d'Ormesson consiguió plasmar una construcción política inventada tan sólida y coherente que impone su presencia ficticia en la imaginación como si fuera real, recurriendo a la eficacia retórica de la historiografía romántica, con profusión de batallas e intrigas, para resucitar el culto de los héroes providenciales como figuras determinantes en el transcurso histórico. Su libro parece entonces una protesta implícita contra la Nouvelle histoire coetánea, que atendía más a las mentalidades que a la política y rechazaba la idea misma de grandes hombres, si bien d'Ormesson tampoco olvida los aspectos socioeconómicos. La Gloire de l'Empire es «o reconstituire minuțioasă a unui imperiu aflat la hotarul dintre real şi fantastic»» (Râpeanu 1996: 16) que persigue crear una historiografía ficticia totalizante cuyo acierto reconoció hasta uno de los representantes principales de aquella Nouvelle histoire, Jacques Le Goff, el cual pareció entender, a diferencia de Duby, que d'Ormesson había 
cultivado un género literario con sus características propias irreductibles a la exigencia científica de verificación, un género que Le Goff reconoce como tal, denominándolo historia-ficción, esto es, fictohistoria (1972: 35):

Ce livre de dilettante, fait en s'amusant et pour amuser, rapiécé de bric et de broc, est une œuvre pionnière. Avec lui naît l'histoire-fiction, s'introduisent en histoire des méthodes de simulation [...] qui peuvent être un instrument sophistiqué d'analyse et d'expérimentation... [Este libro de aficionado, escrito divirtiéndose y por divertirse, remendado con piezas de aquí y de allá, es una obra pionera. Con ella nace la historiaficción y se introducen en la historia métodos de simulación (...) que pueden ser un instrumento complejo de análisis y experimentación...].

Aunque La Gloire de l'Empire no había fundado ni mucho menos el género, ofrecía, pues, motivos de interés tanto para los historiadores como para los amantes de la ficción, habiendo sido bien recibida asimismo como muestra notable de literatura especulativa $^{26}$. Sin embargo, su ejemplo no parece haber suscitado émulos, aparte quizás de Rafael Sánchez Ferlosio, cuyo ciclo de las guerras barcialeas, ocurridas en una Península Ibérica prerromana imaginaria, puede ilustrar una concepción de la historia menos personalista que la adoptada por d'Ormesson. El autor español hace hincapié en la mayor trascendencia a la larga de una obra civilizadora que encuentra su mejor expresión en las obras públicas, como el puente fronterizo entre dos Estados rivales inventados cuya construcción relata en «Los príncipes concordes», después de haber utilizado el mismo universo ficticio para presentar su concepción de la historia en «Los lectores del ayer (Introducción de Ogai el Viejo)» (1980), texto luego recogido también en El geco (2005). Sánchez Ferlosio hace hincapié sobre todo en la ética de los gobernantes como condición del bienestar público, al igual que la historia apócrifa de un soberano quechua inexistente y de su valle andino suspendido en el tiempo contada por Diego Muñoz Valenzuela en «El Valle del Inca» (Nada ha terminado, 1984), la cual se asemeja literariamente, y tal vez como filosofía, a «Historia de Anquises el Silencioso (Cuento oriental)» (Cuentos para salvarnos todos, 1996), de José Ovejero.

Por encima de sus diferencias de concepto, d'Ormesson y Sánchez Ferlosio representan, en cualquier caso, los ejemplos quizá más altos de una fictohistoria reflexiva e intelectual que aspira a participar, al menos simbólicamente, en el debate historiográfico contemporáneo desde la posición difícil y ambigua que supone proponer una fícción intercambiable con la historia no solo en su discurso, sino también en el cuidado extremo de la verosimilitud, difuminando así las fronteras de lo real. Este fenómeno se pro-

26 Por ejemplo, el escritor francés, sobre todo de ciencia ficción, Francis Valéry se refiere a La Gloire de l'Empire en los siguientes términos entusiastas: «Troquant pour un temps son costume d'académicien affable contre celui d'historien érudit, Jean d'Ormesson a écrit un époustouflant pastiche de ces grands récits historiques du XIX ${ }^{\mathrm{e}}$ siècle. Rien n'y manque — pas même les cartes et les références aux querelles des spécialistes ! Aventure romanesque et amoureuse pleine de bruit et de fureur, d'intelligence et de passion, évoluant entre l'histoire imaginaire et l'uchronie, La Gloire de l'Empire est l'une des œuvres maîtresses du sémillant et indispensable Jean d'Ormesson» [Jean d'Ormesson, trocando por un tiempo su traje de académico afable por el de historiador erudito, escribió un pastiche sorprendente de esas grandes narraciones históricas del siglo XIX. No falta nada, ni siquiera los mapas y las referencias a las querellas de los especialistas. La gloria del imperio es una aventura novelesca y amorosa llena de ruido y furia, de inteligencia y pasión, que se mueve entre la historia imaginaria y la ucronía, y es una de las obras maestras del enérgico e indispensable Jean d'Ormesson] (2000: 219). 
duce aún en mayor medida cuando los escritores ni siquiera inventan una geografía imaginaria para sus historias, sino que postulan una visión propia del pasado aduciendo una documentación imaginaria, pero presentada como si fuera genuina. Entonces cabe la duda de si el texto es referencial, al informar de algo verdaderamente ocurrido, o de si se trata de una invención engañosa, al menos hasta que se llega al convencimiento de que son falsos o no existen los documentos aducidos por los autores para justificar ilusoriamente la veracidad de su creación historiográfica, cuyo carácter inventado queda señalado en definitiva por esa misma falsedad o inexistencia de las fuentes aducidas, las cuales señalan así que se trata de una superchería literaria y no de una verdadera falsificación $^{27}$, a diferencia del recurso sesgado a las fuentes para propalar infundios como las elucubraciones más o menos ocultistas sobre la Atlántida, por ejemplo. No obstante, la ambigüedad de este tipo de fictohistoria, que podríamos denominar historia paralela por seguir normalmente el curso histórico documentado (real o filtrado a través de la visión literaria tradicional de la misma), aunque modificándolo de forma más o menos amplia con diferentes propósitos y, en consecuencia, ficcionalizándolo, puede explicar que pueda haberse interpretado a veces como relación auténtica, tal como ocurrió en la Edad Media, por ejemplo, con la Historia de la destrucción de Troya (De excidio Troiae historia, ¿siglo V?) atribuida a Dares Phrygius. Una vez perfeccionados los métodos historiográficos, rara vez se ha creído durante mucho tiempo en la veracidad de unas obras que, al no basar su reconstrucción histórica en documentos fidedignos, además de haber sido creadas a menudo no por historiadores profesionales, sino por literatos que asumen la entera responsabilidad de su escritura, se han solido leer como historias ficticias, con algunas excepciones ${ }^{28}$.

27 La falsificación literaria ha producido algunos textos interesantes de forma historiográfica entre los numerosos que los verdaderos autores han atribuidos engañosamente a escritores inventados o falsos. En los dos últimos siglos, este tipo de mistificaciones literarias ha sido bastante frecuente, por distintas razones (exaltación nacionalista, sátira de la institución literaria y crítica, etc.), pero los falsarios parecen haberse inclinado en general para sus imposturas creativas por la poesía, el drama, la novela o, entre los géneros afines a la historia, a la biografía o las memorias. No obstante, existen algunos importantes ejemplos de falsa crónica como, por ejemplo, Izvodul spătarului Clănău o Cronica lui Huru (1856/1857), una seudocrónica medieval moldava fabricada quizá por Constantin Sion y sus hermanos, la cual fue creída auténtica al principio pese a que la obra ofrecía «detalii picturale care trădează o concepție modernă, sensibilă la culori şi forme, la imagini în general» [detalles pictóricos que revelan una concepción moderna, sensible a los colores y las formas, a las imágenes en general] (Anghelescu 2008: 29). El fraude histórico-textual más famoso se perpetró en Cerdeña, donde salió a la luz «una cronaca di un certo Giorgio di Lacon sulle imprese in Sardegna del saraceno Museto - personaggio realmente esistito - poco dopo il Mille» (Tola 2006: 176), que forma parte, junto con una biografía espuria de Leonor de Arborea atribuida a «Johanne Cupellu de Aristanis» y escrita también en lengua sarda, del conjunto de pergaminos seudomedievales publicados en 1863 y 1865 y conocidos hoy por el nombre italiano de Carte d'Arborea (Cartas de Arborea en sardo común), cuya falsificación fue obra seguramente de Ignazio Pillito. Estas falsificaciones cronísticas pueden leerse hoy, anacrónicamente, como ilusorias historias ficticias que persiguen colmar románticamente lagunas de la literatura en las lenguas propias mediante el aprovechamiento inventivo de los modelos retóricos de la historiografía medieval. Un procedimiento análogo, pero sin ánimo de engaño y con una ironía que anuncia el enfoque postmoderno, sigue Nilson Martello en «Da Mayor Speriencia» (1965), que se presenta como un fragmento de una crónica del siglo XIV, escrita en falso portugués antiguo, en la que se relata un primer contacto con alienígenas.

28 Por ejemplo, el carácter fundamentalmente literario de la sensacionalista Histoire de l'Inquisition en France, depuis son établissement au XIII siècle, à la suite de la croisade contre les Albigeois, jusqu'en 1772, époque définitive de sa suppression (1829), de Étienne-Léon de Lamothe-Langan, no se acreditó hasta bien entrado el siglo XX. En general, los desajustes, deliberados o no, con lo conocido de la Historia son tan evidentes que la mistificación no tiene mucho recorrido. Los ejemplos de ello abundan y bastará para nuestro propósito mencionar la nota «Un război al lui Mircea în 1399 (un document nou)» (1901), de Constantin A. Ionescu-Caion, cuya falsedad puso de manifiesto públicamente Barbu Delavrancea al defender a Ion Luca 
Entre estas historias paralelas que combinan referencialidad e invención en un artefacto esencialmente ficticio de forma historiográfica ${ }^{29}$, se cuentan ejemplos tan notables como la Histoire secrète d'Isabelle de Bavière, reine de France, acabada por Donatien Alphonse François de Sade poco antes de su muerte en 1814, aunque publicada tan solo en 1953. En esta obra, que prolonga y culmina la tradición de las historias secretas de los grandes de este mundo consagrada en Francia por la «nouvelle historique» [novela corta histórica] de escritura historiográfica impecable Dom Carlos (1672), de César Vichard de Saint-Réal, el autor afirma haber consultado unos documentos medievales, luego perdidos durante la Revolución francesa, que cita con toda escrupulosidad científica $^{30}$, para hacer creer en la verdad de lo expuesto. El resultado es una fusión lograda de lo ficticio y lo histórico en un texto típicamente sadiano por sus «[f]antasmes et métaphores pathologiques» [fantasías y metáforas patológicas] (Saint Martin 2009: 529) y por el cual el divino marqués «mérite d'être rangé au nombre des meilleurs tenants de ce genre ambigu qui, très éloigné du roman, en emprunte quelques aspects, et, de la veine de Clio, n'est pas tout à fait l'histoire» [merece contarse entre los mejores paladines de este género ambiguo que, muy alejado de la novela, adopta algunos de sus elementos y, siendo de la vena de Clío, no es exactamente historia] (Lely 1968: 14), esto es, el género que denominamos «fictohistoria». En cualquier caso, esta su última obra puede entenderse como una especie de culminación literaria tanto de la propia producción de Sade como de la historia clásica y su estilo oratorio (Bonnet 1982: 41):

Plutôt qu'un hapax, Isabelle de Bavière est l'accomplissement d'une expérience. Sade colonise vigoureusement le discours historique qui était une référence majeure de ses précédents livres. Il occupe d'autant plus aisément ce terrain étranger que le style historique est encore animé par la chaleur de la rhétorique et de l'éloquence.

El tono de la historias paralelas posteriores suele ser muy distinto, al abundar las que tienen un carácter de broma o guiño a los lectores, a cuya cultura y perspicacia se apela para que aprecien la gracia de su juego seudohistórico. Por ejemplo, la lúdicamente postmoderna Historia abreviada de la literatura portátil (1985), de Enrique VilaMatas describe, con profusión de anécdotas, la evolución de una corriente inexistente de

Caragiale ante los tribunales contra las acusaciones de plagio lanzadas por Caion basándose en documentos que había fabricado este literato-falsario.

29 La adopción del discurso historiográfico es el elemento esencial de la clasificación de estas historias paralelas como fictohistorias. Inversamente, existen también ficciones en forma novelesca que afirman basarse expresamente en una documentación auténtica, pero que es puramente imaginaria. En este caso, nos encontraríamos ante un curioso fenómeno de novelización de un material fictohistórico, esto es, ante un subgénero particular de la narrativa histórica, que podríamos denominar fictohistoria novelada. Tras algún precedente de gran interés como la alegórica «Historia del buen rey Totem (fragmento paleolítico)» (1925; Cuentos sin importancia, 1926), de José María Pemán, un ejemplo contemporáneo muy representativo es el «apologue particulièrement original» [apólogo especialmente original] (Mützenberg 1991: 202) «Il papa che saveva buca crer en Diu» (1987; Il cavalut verd ed auter, 1988), de Ursicin G. G. Derungs, en el que el narrador declara el autor en la propia ficción que había procedido a una modernización expresiva de unas antiguas crónicas, naturalmente inventadas, novelizándolas.

30 «Le charme de ces multiples références à un texte matériellement inexistant est qu'elles sont faites avec tout le sérieux de l'érudition, en nous précisant à chaque fois, dans des notes à pied de page, le numéro de la séance d'interrogatoire ou celui de la liasse de la procédure, et celui du feuillet consulté» [el encanto de las múltiples referencias a un texto materialmente inexistente radica en que se hacen con toda la seriedad de la erudición, precisado cada vez, en notas a pie de pie de página, el número de la sesión de interrogatorio o del legajo del proceso y el pliego consultado] (Thomas 1983: 50). 
la época de las vanguardias históricas, de modo que es «tanto texto de la historia, historia, como texto para la historia, novela» (Blesa 2003: 123), en forma de «parodia de la historia literaria y, en definitiva, de la historiografía» (Blesa 2001-2003: 55), en una línea desmitificadora cultivada también antes por Juan Perucho en las historias paralelas fantásticas y eruditas de Minuta de monstruos (1987). Se trata en estos casos de fictohistorias cuyo envite es sobre todo artístico, lo que puede limitar el alcance especulativo de su reflexión, que se ejerce sobre hechos concretos de alcance a la postre limitado ${ }^{31}$, en vez de hacerlo sobre el devenir de los hombres y las sociedades a la manera en que lo hacen, recurriendo al procedimiento de la analogía, otros subgéneros de la fictohistoria, como aquel en que sus protagonistas son especies no humanas, terrestres o alienígenas. Entre estas últimas destacan por su originalidad los gark de la breve «Dialexis» [1972], de Carlo Frabetti y, sobre todo, la pionera Star ou $\psi$ de Cassiopée, histoire merveilleuse de l'un des mondes de l'espace, nature singulière, coutumes, voyages, littérature starienne, poèmes et comédies traduits du starien (1854), de C. [Charlemagne] - I. [Ischir] Defontenay. Este libro es quizá el más original de los clasificables en el género de la fictohistoria si atendemos al planteamiento predominante del texto, en el que el discurso historiográfico se expresa en prosa y verso y se reproducen, como anexos de la historia, poemas y comedias enteros. Gracias al artificio de la documentación encontrada, el narrador-historiador describe la geografía, las especies (sobre todo inteligentes y humanoides en general) y las civilizaciones de otro sistema planetario, así como su evolución, lo que le da pie a ocuparse "with the problem of philosophical and religious belief and with posibles ways of organizing society» (Zielonka 1986: 321). La obra entera destaca no tanto por su dimensión de ideas, como por el original proceso de «déterritorialisation» [desterritorialización] (Rus 2009: 328 y ss.) imaginativa a que Defontenay somete a los lectores al confrontarlos con todo un universo extraterrestre creado con una riqueza conceptual, metafórica y estilística que sobrepasa en mucho la ciencia ficción posterior, que se anuncia ahí con todas sus características distintivas, incluido su dimensión de fuente de nuevos mitos (Jaccaud 2008: 8):

Habile, le narrateur entraîne le lecteur dans un univers autre en l'impliquant dans ce voyage extra-planétaire. Cet ailleurs se déploie sous nos yeux dans une beauté presque surréaliste; dans son schéma astronomique, dans son ecosystème - de ces oiseauxplantes, de ces bêtes qui volent en se gonflant de gaz - dans ses peuples et leurs histoires. Mais Star, création littéraire au sens plein, ne se restreint pas à la description, ni à l'illustration utopique d'un monde autre. Le livre mosaïque invite au voyage, impose sa vision kaléidoscopique d'un monde qui prend forme au fur et à mésure des sources

31 Un indicio de este carácter limitado, al menos desde el punto de vista histórico tradicional, es la tendencia al mero biografismo, incluso cuando se trata de soberanos cuyo ejercicio del poder tiene consecuencias en la colectividad. Así ocurre en la fictohistoria de Sade y, en mayor medida, en «Nabónides» (Confabulario, 1952), de Juan José Arreola, cuyo modelo para imaginar su visión apócrifa del último rey de Babilonia son los retratos apócrifos de personalidades existentes constitutivos de las Vies imaginaires (1896), Marcel Schwob, si bien Arreola añade el aparato referencial inventado propio de la historia paralela: «Con el fin de lograr la credibilidad propia acerca de los hechos que se cuentan, la historia de Nabónides es referida por una voz anónima y pretendidamente objetiva -que podría ser la de un divulgador científico o un profesor de historia-, cuya principal fuente es un estudio erudito consignado en nota al pie» (González Arce 2010: 90) y cuyo autor, el profesor Rabsolom, no ha existido. No obstante, la fina ironía de Arreola confiere gran atractivo a esta fictohistoria, igual que ocurre en la reconstrucción de un episodio de la vida sentimental de Napoleón a partir de un única frase de una memorias apócrifas en «El ala izquierda del águila» (El retablo de Maese Pedro, 1973, y Más arriba del reino, 1980), de Pedro Gómez Valderrama. 
citées et traduites. [...] Le fond et la forme se réjoignent dans le même but, celui de créer un pur mythe.

Esta obra maestra pasó casi desapercibida en su época, seguramente por adelantarse demasiado a la literatura de entonces, mientras que el triunfo absoluto de la novela en la ficción científica (post)moderna no ha sido muy propicia a una obra en que el marco historiográfico acoge discursos como el poético o el dramático también marginados crecientemente en la práctica lectora. En cualquier caso, no parece que influyera en la fictohistoria posterior $y$, dentro de su mismo subgénero, la mayoría de sus cultivadores ha preferido centrarse en especies reales de nuestro planeta, por lo que se podría denominar historia animal o xenohistoria. Esta parece entroncar sobre todo con la fábula o fantasía esópica, cuya cercanía genérica es patente en un precursor de esta modalidad fictohistórica, a saber, Monarquía Columbina (1790), de Andrés Merino, obra que funde alegoría política con animales (palomas y aves rapaces) y discurso historiográfico clasicista. Esta relación con la fábula se repite, por ejemplo, en «A Sereníssima República (conferência do cônego Vargas)» (Papéis Avulsos, 1882), de Joaquim Maria Machado de Assis, que sería «um conto, em formato de conferência e com uma estrutura de fábula» [un cuento, en forma de conferencia y con estructura de fábula] (Carvalho 2011:3) y que se puede considerar una fictohistoria sui generis expuesta en primera persona por el científico extravagante que ha sometido a una sociedad de arañas a un experimento sociológico que satiriza los usos electorales de su época mediante un procedimiento lucianesco en que se aplica «a desrazão como forma de criticar a razão consensual, caracterizando um processo típico de desconstrução cínica de noções e de hábitos consagrados» [la sinrazón como forma de criticar la razón consensual, determinando un proceso típico de deconstrucción cínica de nociones y hábitos establecidos] (Teixeira 2005: LI). El planteamiento de Machado de Assis no es, pues, estrechamente político, sino más bien moral, pues «[c] hama à atenção a contundente crítica do autor no sentido de que a complexidade ou simplicidade do sistema jurídico-político não é capaz de evitar as ações corruptivas, pois estas derivam da vontade e do caráter dos agentes» (Azeredo Arneitz 2010: 1896).

Reviste un carácter aún más satírico y cruelmente irónico contra todas las instituciones, como correspondía quizás a su escritura justo después de las masacres de la Gran Guerra, La Conjuration des chats (1919-1920), de Roger Avermaete, en que una revuelta futura de los pueblos colonizados de África atrae a los varones europeos en armas, coyuntura que aprovechan los gatos para enviar a mujeres, niños y ancianos a campos de concentración, tras sublevarse contra los humanos. La revolución felina acaba fracasando por razones de incompetencia y dejadez. La historia humana sigue su curso, sin que nadie tome en serio los testimonios de los prisioneros de los campos. Esta fictohistoria amargamente cómica, amén de profética, representa un ataque frontal y cínico al género humano, pues el autor, «[p]our mieux fustiger les hommes, il prête tous leurs défauts aux chats» [para fustigar mejor a los hombres, presta todos sus defectos a los gatos] (Denuit 1979: 142), de manera que la antropormofización resalta su carácter de fábula, una fábula con tintes vanguardistas y tendencia libertaria que se funde, ayudada precisamente por la humanización gatuna, con su planteamiento concurrente de historia prospectiva. 
Si bien mantienen implícitamente su carácter de apólogos, otras xenohistorias modernas se esfuerzan por evitar el antropomorfismo tradicional y por reflejar hasta cierto punto las costumbres de los animales, especialmente de los insectos sociales, tal como hacen, por ejemplo, Adolfo Pérez Zelaschi en una parábola sociológica titulada «Historia general de las hormigas» (Más allá de los espejos, 1949) y atribuida a un supuesto autor noruego llamado Harald Heggstad o «El miligramo prodigioso» (Confabulario, 1950), de Juan José Arreola, una brillante fictohistoria sobre la enajenación religiosa y económica.

Así pues, al igual que la fábula de la que proceden, pero añadiéndole elementos de verosimilitud entomológica que las emparenta con la ciencia ficción, estas xenohistorias también tienen en común con la modalidad fictocientífica su recurso al distanciamiento para expresar juicios de validez universal. A diferencia de las ficciones realistas, cuya ambientación empírica favorece la interpretación de su crítica como si se ejerciera únicamente sobre el aquí y ahora, la adopción exclusiva de la perspectiva del animal obliga al lector a mirarse a sí mismo y a su sociedad desde fuera y a darse cuenta de lo aberrante o ridículo de unos usos dados por supuestos. Sin embargo, este procedimiento, que es tan antiguo como el cuento filosófico o, más aún, como la sátira menipea grecolatina, no es frecuente que adopte el discurso historiográfico, tal vez porque esta forma no parece prestarse demasiado a unos seres, como los animales, a quienes no se les aplica normalmente la posibilidad de tener otra Historia que no sea la natural, la evolutiva. En cambio, la reflexión distanciadora sobre el presente, especialmente en lo relativo a su dimensión sociopolítica, ha encontrado terreno abonado en un tipo de fictohistoria que se asemeja a la historia apócrifa por mostrar también las vicisitudes de entidades geopolíticas imaginarias, aunque el curso de la Historia se simboliza en la historia alegórica mediante figuras y países de nombres inventados que suelen guardar una correspondencia sistemática con tendencias reales de la época del escritor, no de un pasado de una lejanía casi mítica como en la apócrifa. Incluso cuando la historia alegórica tiene una profundidad temporal considerable, la presencia de anacronismos voluntarios la liga a una actualidad que se suele mirar con ojos críticos, de modo que tiende a convertirse en un informe simbólico del presente. De hecho, la sátira predomina en esta modalidad literaria, como sugieren textos tan célebres como L'île des pingouins (1908), de Anatole France, que «se présente comme un ouvrage historique relatant les événements qui sont déroulés en Pingouinie depuis les origines» [se presenta como una obra histórica que narra los acontecimientos sucedidos en Pingüinia desde los orígenes] (Gascar 1980: 12), esto es, como una historia de Francia desde su principio hasta un futuro vaticinado relatada mediante una fusión de alegoría y fábula, ya que sus personajes son los pingüinos del título, en una construcción narrativa compleja en forma de fictohistoria novelada en la que los pasajes de intención y apariencia historiográficas conviven con abundantes rasgos novelísticos (por ejemplo, abundan los diálogos).

Sí parecen claramente fictohistóricas la argentina anónima Aureópolis (1891), sobre todo su marco ${ }^{32}$, y, más modernamente, la recopilación de Crónicas reales (1967),

32 «Una vez establecido el marco alegórico, el texto abandona toda pretensión ficcional. No hay diálogos ni personajes imaginarios; el sujeto de la enunciación es una voz omnisciente que se limita a relatar los avatares del país desde la caída de Rosas hasta la víspera de las elecciones presidenciales de 1892, con el tono seco y expositivo de un libro de historia» (Abraham 2013: 362). 
de Manuel Mujica Láinez ${ }^{33}$ Estas revelan el irónico escepticismo del autor sobre la naturaleza humana, así como «su visión humorística y desmitificadora de la Historia, aproximándola no solo a la "pequeña historia" sino también a la ficción» (Cruz 2001: 25), al tratarse, precisamente, de fictohistoria. El libro «is composed of eleven episodes from the history of an imaginary Eastern European country, spanning from the early Middle Ages to "now"» (Schanzer 1986: 90), siguiendo una secuencia cronológica, aunque no sistemática. Las crónicas relatan los altos hechos de una excéntrica dinastía en una lograda amalgama barroca, a partir de fuentes recreadas por un narrador que «se propone contarnos la Historia de su país con las garantías de un historiador objetivo y cientifista» (Cerrada Carretero 1990: 606).

Asimismo, existen ejemplos de historia alegórica seria, incluso trágica, como la parábola malthusiana «Mahavir o della populazione crescente» (Le pazzie del poeta, 1950), de Giovanni Papini; la curiosa «crónica» de dictador «El filántropo» (1965; Los huéspedes, 1968), de Segundo Serrano Poncela, o la kafkiana «El rascacielos» (Amor siempre asediado y otros relatos, 1989), de Antonio Menchaca, además de varias de las breves ficciones en torno a ciudades alegóricas («Tropaeum», «Seneția», «Protopolis», «Castrum», «Musaeum», «Homogenia», «Cosmovia», «Geopolis») del «fals tratat de urbogonie» [falso tratado de urbogonía] de George Săsărman titulado Cuadratura cercului (1975/2001), cuya ironía muy borgiana se combina con una reflexión poética sobre los destinos urbanos, al igual que ocurre en otras colecciones similares ${ }^{34}$. No obstante, la historia alegórica suele presentar más bien rasgos paródicos e incluso absurdos, cuando no maravillosos ${ }^{35}$, tal como ocurre, por ejemplo, en sátiras del imperialismo, el racismo y la explotación (política, económica, religiosa, cultural, etc.) como «De la prehistòria a la civilització» (1928), de Àngel Ferran; «Războiul celor 43 de zile», «Rasa pură»y «Protocolul de la Modena» (Avantajul de a fi câine, 1938), de Ştefan Tita; «Censura in Bitinia» (1961; Storie naturali, 1966), de Primo Levi; «I Cacciatori di Teste» (Viaggio in Drimonia, 1965), de Lia Wainstein; «Sigue Poeta» (1969), de Manuel Derqui, o «Ils plats» (Il cavalut verd ed auter, 1988), de Ursicin G. [Gion] G. [Geli] Derungs. La institución literaria en su marco social se cuestiona en otras historias alegóricas, también burlescamente irónicas, como «La literatura no se cotiza» $(1937 ; E l$ laurel de San Lorenzo, 1959), de Antonio Castro Leal, y sus predecesoras muy logradas «La conquista de la Luna» y «Era un país pobre» (Ensayos y poemas, 1917), de Julio Torri, en las que «[1]a intención irónica del escritor [...] se revela sobre todo mediante el contraste entre el tono objetivo del narrador y el carácter exagerado y absurdo de lo

33 Mujica Láinez publicó a continuación De milagros y de melancolías (1968), que guarda fuertes semejanzas temáticas y estructurales con Crónicas reales al narrar la historia de una imaginaria ciudad hispanoamericana y de su evolución desde su fundación colonial hasta el futuro. Sin embargo, la presencia de diálogos novelísticos indica que se trata más bien de una fictohistoria novelada a la manera de la mencionada de Anatole France $\mathrm{y}$, como en esta, el autor argentino «[i]magina y construye espacios netamente ficcionales, supuestos hitos históricos (igualmente ficcionales), así como, a veces, personajes deliberadamente absurdos en sus acciones representadas» (Marcos Fernández 2013: 96).

34 Entre ellas destaca Cidades inventadas (1997), de Ferreira Gullar (José Ribamar Ferreira), más de la mitad de las cuales adopta el discurso historiográfico («Vat Phan», «Tyfw», «Texclx», «Fraternópolis», «Tuxmu», «Minofagasta», «Iscúmbria», «Inoa», «Zambarbirna», «Wen-Fen», «Mori», «Bela» y «Adrixerlinus») para proponer alegorías de ciudades históricas reales en forma de una parodia que «apresenta opções ficcionais para ocupar o espaço de um possível vazio deixado pela História» (Lins Precioso 2007: 39).

35 Se podría mencionar a este respecto la reescritura fictohistórica del famoso cuento de hadas «La Bella Durmiente: una historia económica» (Porvenir, 2007), de Iban Zaldua. 
narrado» (Zaïtzeff 2011: 55-56). También se puede mencionar un ejemplo muy curioso, por su asunto astronómico y futurista, titulado «Acunamiento» (Libro sin tapas, 1929), de Felisberto Hernández, cuyo tema y tratamiento vanguardista coinciden con los de «Congresso Pamplanetário» (Histórias e Sonhos, 1920), historia en la que Afonso Henriques de Lima Barreto ${ }^{36}$ «faz uma abordagem das relações internacionais com traços de uma alegoría em forma de ficção científica» [aborda las relaciones internacionales con rasgos de una alegoría en forma de ficción científica] (Pereira de Almeida 2009: 74). «Incomunicabilità 1» (Esempi di avvenire, 1965) e «Incomunicabilità 2» (Carezzate con terrore la testa dei vostri figli, 1992), de Roberto Vacca, también combinan tragicocómicamente historia alegórica y ciencia ficción al proponer explicaciones de este último tipo a la historia del cáncer y el misticismo, respectivamente. Los rasgos burlescos y disparatados presentes en bastantes de las historias alegóricas recordadas confieren a esta modalidad fictohistórica una agradable ligereza en general, además de realzar la dimensión literaria, ficticia, de lo relatado por encima de los lazos que mantiene con la realidad histórica, que se refleja con una deformación más o menos marcada. Esos vínculos con un referente real concreto que se traspone alegóricamente ancla este tipo de fictohistoria en una geografía y tiempo concretos, en detrimento a veces de una visión más general. En cambio, y aparte de las anticipaciones políticas a corto plazo y ámbito estrechamente nacional, la historia del futuro, que también suele partir de espacios y objetos históricos realmente existentes, se presta no solo a un análisis más o menos didáctico de las tendencias actuales observadas desde la perspectiva supuestamente imparcial del porvenir, sino también a la creación de panoramas en que toda la humanidad y su Historia es lo que se ventila ficticiamente.

\section{Bibliografía citada}

ABRAHAM, Carlos (2013): La literatura fantástica argentina en el siglo XIX (sobre «Aureópolis», pp. 361-363). Colmenar Viejo: La Biblioteca del Laberinto.

ANGHELESCU, Mircea (2008): «Reconstituirea istoriei», in Mistificțiuni: Falsuri, farse, apocrife, pastişe, pseudonime şi alte mistificații în literatură, pp. 17-46 (sobre Cronica lui Huru, pp. 27-46). Bucureşti: Compania.

ANTOHI, Sorin $\left(2005^{2}\right)$ : Utopica: Studii asupra imaginarului social. Cluj: Idea Design \& Print.

AZEREDO ARNEITZ, Juliana (2010): «O Direito sob o véu da literatura: Entre homens e aranhas», in Anais do XIX Encontro Nacional do CONPEDI. Tema: "Direitos Fundamentais e Transdisciplinaridade»9, 10, 11 e 12 de Junho de 2010 Fortaleza - CE, pp. 1892-1899 (sobre «A Sereníssima República», de Joaquim Maria Machado de Assis). Florianópolis: Fundação Boiteux.

BADEA-GHERACOSTEA, Cătălin $\left(2010^{2}\right)$ : «Studiu de caz: Motocentauri pe Acoperişul Lumii», in Alternative critice, pp. 85-124 (sobre «Scurtă istorie generală a lucrurilor», pp. 91-92, 97-98, 105-106, 111-112). Satu Mare: Millenium Books.

36 El mismo autor escribió otra fictohistoria breve, «O falso dom Henrique V (Episódio da história da Bruzundanga)» (1921), que adopta un planteamiento amargamente burlesco cercano al de las posteriores Crónicas reales de Mujica Láinez. Además, transpuso alegóricamente la Historia moderna de Brasil como si fuera un sultanato islámico en varias de sus ficciones, de las cuales tres adoptan la forma historiográfica, a saber, «A firmeza de Al-Bandeirah», «A solidariedade de Al-Bandeirah» y «O reconhecimento», todas ellas de 1915. 
BARRAL, Carlos (1980): «La creación léxica.- Fictohistoria». La Vanguardia 35622 (24 de diciembre): 7.

BARTHES, Roland (1984): «Le discours de l'histoire» (1967), in Le Bruissement de la langue. Essais critiques IV, pp. 163-177. Paris: Seuil.

BLESA, Túa (2003): «Un fraude en toda regla: Historia abreviada de la literatura portátil, 1», in Túa Blesa, María Antonia Martín Zarraquino (eds.), Homenaje a Gaudioso Giménez Resano. Miscelánea de estudios literarios y lingüísticos, pp. 123-133. Zaragoza: Universidad de Zaragoza - Institución «Fernando el Católico» (C.S.I.C.).

(2001-2003): «Un fraude en toda regla: Historia abreviada de la literatura portátil, 2». Tropelias 12-14: 45-58.

BONNET, Jean-Claude (1982): «La harangue sadienne». Poétique 13, 49: 31-50.

CARVALHO, Vinicius Mariano de (2011): «Quando a consulta popular é uma fábula O conto Sereníssima República de Machado de Assis como interpretação da democracia direta na América Latina». Diálogos Latinoamericanos 18: 1-9.

CERRADA CARRETERO, Antonio (1990): «Crónicas reales», en La narrativa de Manuel Mujica Láinez, 1, pp. 606-640. Madrid: Universidad Complutense de Madrid.

CHRISTENSEN, Peter G. (1990): «History and the Possibility of Wisdom en Jean D'Ormesson's La Gloire de l'empire». The International Fiction Review 17, 2: 8287.

CLEMONS, Gregory A. (2008): «The Use of Humor en Manuel Mujica Láinez's Crónicas reales». Hipertexto 8: 3-21.

COHN, Dorrit (1999): «Signposts of Fictionality», in The Distinction of Fiction, pp. 109-131. Baltimore, ML: The John Hopkins University Press.

CRUZ, Jorge (2001): «Prólogo», in Manuel Mujica Láinez, Cuentos completos, 1, pp. 11-30 (sobre Crónicas reales, pp. 22-25). Madrid: Alfaguara.

DE BONI, Claudio (2003): «Renouvier e il fascino della "ucronia, in Descrivere il futuro. Scienza e utopia en Francia nell'età del positivismo, pp. 65-74. Firenze: Firenze University Press.

DENUIT, Désiré (1979): Roger Avermaete le non conformiste (sobre La Conjuration des chats, pp. 138-143). Bruxelles: Fonds Mercator.

FASANO, Marina Lessona (1998): «Contro-passato prossimo», in Guido Morselli. Un inspiegabile caso letterario, pp. 93-116. Napoli: Liguori.

FRANCCEUR, Louis (1988-1989): «Pour une sémiotique des traces». Études littéraires 21, 3: 177-194.

GASCAR, Pierre (1980): «Préface», in Anatole France, L'Île des pingouins, pp. 9-21. Paris: Calmann-Lévy, 1980.

GEFEN, Alexandre (2002): «Vie imaginaire et poétique du roman au XIX ${ }^{\mathrm{e}}$ siècle : la Notice biographique de Louis Lambert». Littérature 128: 3-25.

GENETTE, Gérard (2004): «Récit fictionnel, récit factuel», in Fiction et diction, pp. 141-168. Paris: Seuil.

GONZÁLEZ ARCE, Teresa (2010): «Reflejos de Schwob en Arreola: vidas imaginarias en "Nabónides" y "Epitafio"». Revista de filología y lingüistica de la Universidad de Costa Rica 36, 2 (2010): 87-99 (sobre «Nabónides», pp. 90-92).

GRENIER, Hubert (1988): «Uchronie et utopie chez Renouvier». Corpus 10: 171-194.

GRILLET, Thierry (2000): «L'Uchronie de Charles Renouvier: l'histoire comme hypothèse perpétuelle». Revue de la Bibliothèque Nationale de France 4: 51-56. 
GUISSARD, Lucien (1990): Roman et Histoire. Bruxelles: Académie royale de langue et de littérature françaises de Belgique. Internet:

http://www.arllfb.be/ebibliotheque/communications/guissard13011990.pdf

HENRIET, Éric B. (2004): L'Histoire revisitée. Panorama de l'uchronie sous toutes ses formes. Amiens: Encrage.

INIESTA, Amalia (1986): «Una perspectiva de Crónicas reales de Manuel Mujica Láinez». Anales de literatura hispanoamericana 15: 149-158.

JACCAUD, Frédéric (2008): «C.-I. Defontenay, l'esthète visionnaire», in C.-I. Defontenay, Star ou $\Psi$ de Cassiopée, pp. 5-9. Dinan: Terre de Brume.

JEANDILLOU, Jean-François $\left(2001^{2}\right)$ : Supercheries littéraires: la vie et l'œuvre des auteurs supposés. Genève: Droz.

JEANNELLE, Jean-Louis (2008): Écrire ses Mémoires au XX siècle. Déclin et renouveau. Paris: Gallimard.

LEDUC, Jean (1999): Les Historiens et le temps. Conceptions, problématiques, écritures. Paris: Seuil.

LE GOFF, Jacques (1972): «Une œuvre pionnière», in Jean d'Ormesson, La Gloire de l'Empire, p. 35 (dossier). Paris: Le Cercle du nouveau livre - Librairie Jules Tallandier.

LELY, Gilbert (1968): «Avant-propos», in Marquis de Sade, Histoire secrète d'Isabelle de Bavière, reine de France, pp. 5-16. Paris: Union Générale d’Éditions.

LINS PRECIOSO, Adriana (2007): «A História revista: O espaço da paródia nas Cidades inventadas de Ferreira Gullar». Ecos 6: 34-39.

LOZANO, Jorge (1987): El discurso histórico. Madrid: Alianza.

MARCOS FERNÁNDEZ, Sergio (2013): «M. Mujica Láinez: humor paródico y réplica literaria frente a lo alterno: De milagros y de melancolías». Lingüística y Literatura 34, 63: 95-115.

MARROU, Henri-Irénée (19756): De la connaissance historique. Paris: Seuil.

MARTÍNEZ DURÓ, Manuel (2007): «La historia como artificio: imitación de modelos textuales historiográficos en Herrumbrosas lanzas de Juan Benet». Crisol 11: 87112.

MERELO SOLÁ, Alfonso (2009): «La historia que no fue: A propósito de "Cuatro siglos de buen gobierno" y la otra historia de Nilo María Fabra». Ubi Sunt? Revista de Historia XII, 24: 103-107.

MINERVA, Nadia (1995): «Utopia e mito napoleonico: La Philosophie du Ruvarebohni di Pierre-Ignace Jaunez-Sponville e Napoléon apocryphe di Louis Geoffroy», in Utopia e... Amici e nemici del genere utopico nella letteratura francese, pp. 209-219 (sobre Napoléon apocryphe, pp. 215-219). Ravenna: Longo.

MORA, Carmen de (1997): «Introducción», in Juan José Arreola, Confabulario definitivo, pp. 9-62 (sobre «El prodigioso miligramo», pp. 23-25). Madrid: Cátedra.

MÜTZENBERG, Gabriel (19912): Destin de la langue et de la littérature rhétoromanes. Lausanne: L'Âge d'Homme (sobre «Il papa che saveva buca crer en Diu», de Ursicin G. G. Derungs, pp. 202-203).

PELEGRÍN CAMPO, Julián (2010): «La historia alternativa como herramienta didáctica: una revisión historiográfica». Proyecto Clio 36. Internet:

http://clio.rediris.es/n36/articulos/pelegrin.pdf (consultado por última vez el 27 de noviembre de 2012).

PEREIRA DE ALMEIDA, Carlos (2009): «A exclusão denunciada: o insólito como resistência», in A Solidão como Resistência: Uma Leitura da Configuração da Ação 
Política em Narrativas de Lima Barreto, pp. 67-77 (sobre «Congresso Pamplanetário», pp. 74-77). Campina Grande: Universidade Estadual da Paraíba.

POMIAN, Krzysztof (1999): Sur l'histoire. Paris: Gallimard.

RÂPEANU, Valeriu (1996): “"Orice romancier se crede un Dumnezeu. Orice romancier încearcă să-l imite pe Dumnezeu"», in Jean d'Ormesson, Gloria imperiului, pp. 516. București: Universal Dalsi.

RICCEUR, Paul (1991): «L'historie et le récit», in Temps et récit. I. L'intrigue et le récit historique (1983), pp. 171-396. Paris: Seuil.

RODIEK, Christoph (1997): «Geoffroy: Napoléon et la conquête du monde»; «Renouvier: Uchronie (L'utopie dans l'histoire)»; «Morselli: Contro-passato prossimo», in Erfundene Vergangenheit: Kontrafaktische Geschichtsdarstellung (Uchronie) en der Literatur, pp. 67-76; pp. 77-89; pp. 100-108. Frankfurt am Main: Vittorio Klostermann.

RUS, Martijn (2009): «Un voyage imaginaire aberrant: Star ou Psi de Cassiopée (1854) de Charlemagne-Ischir Defontenay». Poétique, 159 (2009): 325-337.

SAINT MARTIN, Armelle (2009): «Fantasmes et métaphores pathologiques dans l'Histoire secrète d'Isabelle de Bavière». The French Review 82, 3: 529-544.

SCHANZER, George O. (1986): "Crónicas reales», in The Persistence of Human Passions: Manuel Mujica Laínez's Satirical Neo-Modernism, pp. 89-93. London: Tamesis Books.

STALEY, David J. (2002): «A History of the Future». History and Theory 41: 72-89.

TEIXEIRA, Ivan (2005): «Pássaro sem asas ou morte de todos os deuses. Uma leitura de Papéis Avulsos», in Machado de Assis, Papéis Avulsos, pp. IX-LIII (sobre "A Sereníssima República», pp. XLIX-LI). São Paulo: Martins Fontes.

THOMAS, Chantal (1983): «Isabelle de Bavière, dernière héroïne de Sade», in Michel Camus, Philippe Roger (eds.), Sade, écrire la crise, pp. 47-66. Paris: Pierre Belfond.

TOLA, Salvatore (2006): «Il falso e il vero: Le Carte d'Arborea», in La letteratura en lingua sarda: Testi, autori, vicende, pp. 175-179. Cagliari: CUEC.

TORRES CABALLERO, Benjamín (2004): «Prólogo», in Edgardo Rodríguez Juliá, La renuncia del héroe Baltasar, pp. 9-44. México: Fondo de Cultura Económica.

VALÉRY, Francis (2000): «1971 - Jean d'ORMESSON, La Gloire de l'Empire», in Passeport pour les étoiles. Guide de lecture, pp. 217-219. Paris: Denoël.

VERSINS, Pierre (1972), «Histoire future», in Encyclopédie de l'utopie, des voyages extraordinaires et de la science-fiction, pp. 419b-423b. Lausanne: L'Âge d'homme.

WAGAR, Warren W. (1998): «Past and Future». The American Behavioral Scientist 42, 3: 365-371.

WHITE, Hayden (1975): Metahistory: The Historical Imagination en Nineteenth Century Europe (1973). Baltimore, ML - London: The John Hopkins University Press.

ZAÏTZEFF, Serge I. (2011): «El arte de Julio Torri», in Julio Torri, Obra completa, pp. 9-92 (sobre «La conquista de la Luna» y «Era un país pobre», pp. 55-57). México: Fondo de Cultura Económica.

ZIELONKA, Anthony. «Defontenay's Star as poetic and philosophical science fiction». French Forum 11, 3 (1986): 317-333. 